\title{
Analysis on the Problems in Education -A Case Study on the Film an Education
}

\author{
Chuning $\mathrm{Xu}$ \\ Suzhou Experimental High School AP Center, 72 Jinshan Road, New District, Suzhou, Jiangsu Province, 215011, \\ China \\ Corresponding author's e-mail: Vivian.wang@cas-harbour.org
}

\begin{abstract}
An education is a British film directed by the famous Danish female director, screenwriter and producer, Lone Scherfig. The background of the story is set in the 1960s in London, England. Through the analysis on the plot of this film and combining with the heroine's own personal background and experience, the inconsistency in education ideal and education practice is discussed in this paper. Besides, the imbalance in the purpose of education as the excessive emphasis on utilitarian aspect of education and lack of value-orientation guidance for students, as well as its possible outcomes and the impacts are analyzed. This paper calls for the society and the masses to utilize critical thinking and subversive innovative angle of view to re-examine the current education system, reshape and clarify the significance of education. Moreover, the utilitarianism of education in the existing education system should be re-considered, and people should select appropriate corresponding education materials and content. In addition, eliminating the fuzziness on the purpose of education in hearts of the society, teachers and students should be attached importance to. Only in this way the educational goal of "developing the abilities as well as cultivating the person itself" can be eventually achieved .
\end{abstract}

Keywords: Education, imbalance in education, utilitarianism, ambiguity of purpose, social orientation

\section{INTRODUCTION}

With the rapid development of economy and society and the increasing competitive pressure, education plays a more and more important role. On the one hand, education contributes to accumulating knowledge and skills, improving person itself and advancing the society. On the other hand, education affects the chances of employment for people. A highly educated individual is probably to get a good job[1]. Based on relevant online research, this study mainly focuses on the inconsistency in education ideal and education practice, overemphasis on utilitarianism of education and the social orientation of entering the upper class. Besides, the author puts forward several possible reasons for the existing educational problems: higher and higher requirements on academics in order to cope with the increasingly fierce competition in the rapidly developing world; more and more serious social stratification; the ambiguity of educational purpose in society, as well as the students' lack of the advocacy on the core of education. At last, the advantages and disadvantages of the current education system will be discussed. Furthermore, the author attempts to investigate what people can do to deal with the existing problems of education.

\section{THE IDEAL EDUCATION}

When speaking of the significance of education, it is impossible for us to reach a consensus. Just as the saying goes, there are a thousand Hamlets in a thousand people's eyes. In this essay, the ideal education is defined as the education that not only helps people develop academic competence and provide skills training, but also emphasizes the quality education and psychological enhancement.

There are many people who support the definition of education above. According to Martin Luther King Jr., "Intelligence plus character-that is the goal of true education."[2]. According to James Harvey, a senior fellow at the Center on Reinventing Public Educatione, $92 \%$ of parents think that schools have a duty to support the well being and mental health of students[2], while more than half $(53 \%)$ want more information about what their child's school is doing to promote it[6].

To further explain the concept and help the audiences have a better understanding on the goal of education, according to Article 26 of the Universal Declaration of Human Rights (1948): "Education shall be directed to the full development of the human personality and to the strengthening of respect for human rights and fundamental freedoms". Based on this international legal framework, students must receive a quality education that enables their personalities, talents and abilities and to live a full 
and satisfying life within society. Basic skills include not only literacy and numeracy but also life skills such as the ability to make well-balanced decisions; to resolve conflicts in a non-violent manner; and to develop a healthy lifestyle, good social relationships and responsibility, critical thinking, creative talents, and other abilities which give children the tools needed to pursue their options in life[3].

\section{CURRENT SITUATION}

It should be admitted that under the current educational model, there must be a segment of the population who benefit, learn and success as well. It seems that whether someone achieve success or not is a matter of individual probability. However, it may be a matter of reciprocity, that is to say, a limited number of individual success is a product of contemporary education. Moreover, there are inconsistencies between the Ideal education and the education practice and too much emphasis on the utilitarianism of education.

School education only pursues high scores and admission to higher schools, not quality education and personality development, which is referred to the utilitarianism of education. According to David Carless, the problem is a culture where the grade is valued more highly than learning[4].

The education minister, Ong Ye Kung, identified four trade-offs in any educational system: between hard work and student enjoyment; between useful academic differentiation and an over-competitive culture; between customization to cater for a range of abilities and stigmatization of the less academically able; and between skills and paper qualifications[4].

To be more specific, the definition of "the imbalance of education emphasis" is extended as follows:

- Excessive emphasis on written educational materials and teaching models

- Utilitarianism of education prevails (e.g. completing graduation, entering an institution of higher learning, being competitive in job market and other indicators). As to the movie, an education, that will be discussed later in the paper, utilitarianism refers to two aspects: the overall environment background of traditional education in which the heroine lives and the social value orientation for entering the upper class as the ultimate goal of life.

- Lack of quality education: basic skills including life skills such as the ability to make well-balanced decisions and healthy personality such as sense oof responsibility, critical thinking, creative talents, and other abilities that enable children to pursue their options in life.

\section{THE UTILITARIANISM OF EDUCATION}

\subsection{The utilitarian behavior of Jenny's father}

A child's education status is related to many factors, including family environment, economic conditions, parents' education level and their personal qualities, etc. Therefore, the limitations of parents themselves will greatly affect the education of children.

\subsubsection{Plot 1}

There is a scene in the movie where Jenny and her father, Jack, were having a family discussion at the dinner table. When Jenny asked her father if she could play the cello, Jack thought that Jenny's current interest in cello was enough to cope with the question "what are your interests?" from the admissions officer at Oxford, so there is no need for further practice. He also considered that "Hobby needs no practice". Jenny argued that if that meant that she did not have to go to the youth orchestra any more since she had already joined in. Nevertheless, Jack immediately stopped Jenny because he thought Oxford did not like quitters. Jack's starting point is not to cultivate Jenny to be a real talent or develop her ability of critical thinking but to be a so-called "qualified" candidate for Oxford.

\subsubsection{Plot 2}

Jenny raised a question to her parents that what if she chose to get married instead of going to college? Jack's response was it depended on who she got married. If she chose to marry David, the rich man from high social class, then maybe there was no need for her to go to Oxford. Jenny got far more confused and surprised that if she just needed to marry a wealthy man, why not her father just let her hang out in the nightclub? Jack's answer was even more shocking that David would not be interested in Jenny if she was not well-educated. From Jack's perpective, education seems to be a trade.

\subsubsection{Plot 3}

Jack compared Graham, a young classmate who was a kindred spirit, with David and thought that Graham would never surpass David. Jenny defended Graham as a boy who had the potential to become a writer. However, Jack argued that "becoming one is not the same as knowing one." 


\subsubsection{Analysis}

The analysis of the movie suggests that the ultimate goal of Jenny's parents is to get their daughter to enter the upper class no matter via which form: going to Oxford or marrying a rich man like David. They are not averse to the potential opportunities or shortcuts in life. For example, when the wealthy David appeared, the previous strict parents changed their attitude immediately. They showed hospitality to this strange middle-aged man and even encouraged their daughter to drop out of school, give up Oxford and marry him. To sum up, when there are some faster or easier accesses in life that can help them enter the upper class, such as marrying someone with money and high social status like David, they will choose that option without hesitation, because going into the upper class was the ultimate goal for them but not the education. Ambiguous purpose of education and the value orientation of social stratification cannot take off. The cost benefit analysis done by the heroine and her parents is a clear reflection of that they regard education as a way to get a so-called better life, social status or money.

On the other hand, it can reflect how the utilitarianism of education let people ignore the original, real ideal goal of education and focus too much on short-term target without giving consideration to the long-term impact of education. Students, who receives those kind of education like Jenny received, can hardly perceive the fun and interesting parts of study.

\subsection{Impact amplification}

Is this only a story about a misguided girl? If so, why Jenny's parents were also deceived and allowed their daughter not to go to Oxford but to marry a man in an inappropriate age? Even worse, this might not only the way a family views education, but also the misdirection of society towards the concept of education. The social orientation attaches greater importance to entering the social class due to the serious condition of the social stratification.

Jenny was a lucky girl, because of her previous excellency and family conditions, she had the capital to go back to study, get help from teachers, and enter an advanced university like Oxford. However, it is for sure that Jenny was not the only one who was misguided, there were more victims in shadows. However, not everyone is as lucky as Jenny.

\section{FLAWS IN THE EDUCATION SYSTEM}

\subsection{The lack of practical living skills of the education}

According to Martin Luther King Jr., "The function of education is to teach one to think intensively and to think critically."[5] In the plot setting, even though Jenny was almost good at all the academic subjects at school, she failed to identify what a person David really was and even fell into the trap of the fame and wealth. It can be seen that the educational content in textbooks at that time lacked practicability and basic guidance to distinguish right from wrong, which means that students did not develop the abiltiy to think critically. This opposes the ideal of education put forward by Martin Luther King and the definition of ideal education proposed by this paper.

\subsection{The passive choice of Jenny}

Notice that when Jenny found out that David was actually a thief and somewhat a speculator who did improper business, even if she was angry and disappointed at the very beginning, she hastily forgave David and tacitly approved his behavior. Everything went dramatically smooth until Jenny accidentally found out David's marriage via the signature on the letters. This means that Jenny neither wanted to really get rid of this relationship if nothing outrageous took place nor was tired of the wealth and status obtained through improper ways. In other words, the reason why she had made up her mind to make a decision to make a clear break with David is because she feels cheated and betrayed spiritually and emotionally, or because of her self-moral condemnation. The reason why the hero in the movie was abandoned lies in his concealment of his marriage, which is unacceptable to any traditional family. As a result, Jenny and her parents had to give up this shortcut to the upper class and returned to the choice of Oxford.

\subsection{The ambiguous purpose of education}

\subsubsection{The response provided by the headmistress and the speechless of Miss. Stubbs}

It is a pity that both Miss Stubbs and the headmistress, two representatives of well-educated intellectual women, failed to give a persuasive reasoning that can convince Jenny or any other of the audiences. Miss Stubbs's speechlessness is a feeble argument "Go to Oxford no matter what or you break my heart" and the headmistress's equivocal, ridiculous response: civil service. Jenny's sympathy towards Miss Stubbs's experience of graduating from the other famous university, Cambridge, but having to stay in this girl's school and correct boring, tedious compositions is also ironic. Why we need to work hard, get good grades and go to college via our own efforts not instead of marrying with a man who could contribute to your career and help you get "success" via a shortcut? When we connect this question to the plot in the movie, it changes into why Jenny is supposed to or is expected to go to Oxford instead of marrying with a single powerful man if he indeed loves Jenny completely and purely and 
can help Jenny enter into the social class she and her family have been always dreamed of? Instead of attributing the problem into the quality of teachers, it is more appropriate to come down to the whole social atmosphere. Since these teachers were also the "products" or the students of the social orientation.

The reason why Jenny had such a thought is that she had been oppressed by her parents and her studies at school. She was dissatisfied with the current situation, but she was helpless to change it. When she met David and finally felt that her soul has been set free to pursue the life she wanted, she jumped out of the system and began to question the system and all the people who were trying to stop her from jumping out of the system. It is needed to attach great importance to that Jenny is not the only one who feels this way. Thousands of students feel this way. Some are conformists, some are rebels, some are victims of education systems.

\subsubsection{Quotation in film, "Nobody speaks Latin."}

The other detail that required us to think about is a quotation from a friend of David, Helen, an eye-candy beside Denny (colleague and close friend of David)_ “many years ago, nobody speaks Latin." She told the ruthless truth about the useless of some utilitarian education. This is important since without spiritual or further understanding the reason why we need to pass on these outdated cultures, it is hard to help a student or a teenager to find out interest and value of those bald knowledge anyway.

\section{DISCUSSION}

This paper is not aimed at discussing the advantages or the disadvantages of the existing education systems in the world, criticizing or highly phrasing any of them. In the following part of the discussion, the paper will extend according to the small headlines. The development of human civilization cannot be achieved overnight. We might not come up with the perfect solution for everyone, but we need to keep innovating, thinking critically and being kind. Be thankful to the status quo, then give suggestions and make improvements. It seems to be tough and endless, however, someone has to be on the road to explore.

Nowadays, more and more people realize the significance of education, It is common for a family to sacrifice everything it has or even to give away something over what it could afford to help them children admit to university to change the whole family's life and destiny. "A village supports a college student" is also usual in some areas that are not that developed. However, after they are admitted to the university, some students just have hold the belief that the college entrance examination is the end and they start to indulge themselves. In the documentary, Gaokao, the college entrance examination in China, when shooting the representatives of the cramming method of teaching, MaoTanChang Middle School of Anhui Lu'an, a graduate student from this school was recorded to describe her life in college in such a way: "Every day I sleep until 12:00 noon, my roommates help me get the lunch, and then I go back to sleep after eating." This is the tragedy of the exam-oriented education. Those children will definitely find out quickly that the end of the College Entrance Examination is neither the destination of life nor the terminus of the study. Utilitarian education may bring efficient short-term benefits, but it is difficult to maintain the happiness of students. It fails to cultivate students' ability to learn about the world or main the balance of work and life. Perhaps not "education changes destiny" but "knowledge changes destiny". "Learned" and "knew" are two distinct concepts.

\subsection{Scores stand for ability?}

There is no doubt that grades or scores partially reflect the academic ability of a student. Nevertheless, with the rapid competition increases, all kinds of education organizations like tutorial classes, interest-oriented class could help students improve their grades through accumulating exam experience via practicing tons of questions or utilizing exam techniques. Is this kind of 'high score' able to represent the learning ability of a student? According to a recent survey of U.S.-owned enterprises conducted by the American Chamber of Commerce in Shanghai, 37 percent of the responded companies said that finding talent was their biggest operational problem[7]. Everyone is anxious about losing at the starting line. _- It has already been not only children who are learning, but also the parents. One chemistry teacher once mentioned that when she first got her first grade pupil daughter's homework upon the Mathematical Olympiad problem, as a PhD in Chemistry, she got confused and hesitated.

However, this kind of utilitarianism is inevitable, since it results in the social orientation. Some countries may not really want to implement those exam-oriented education policies, but the increasing competition and the large demand of high quality workforce put them in a position where they must do the trade-offs. For example, the increasingly tough SAT scores required on the international market for parts of Asia incentive the utilitarianism in Asia.

\subsection{Utilitarianism is necessary and evolution is inevitable.}

Existence is not necessarily to be reasonable but it must have its reason for existing. Rather than criticizing the flaws of utilitarian education, it is better to consider it as a indispensable step of education evolution process which is just like how a silkworm breaks its cocoon and becomes a butterfly. When the society progresses to a certain 
standard when people's living standard are improved far better than currently and everyone has the access and ability to high-quality education instead of the opportunity to receive education, then the civilization will be advanced. Meanwhile, this evolution is inevitable.

Even though the environment is exam-oriented, if one is lucky enough to come into contact with a more diverse education and his/her family is powerful enough to support a different choice, as a beneficiary in another system, he/she should be grateful to be able to find a system that is suitable for him/her. Yet it is unreasonable to prioritize this education system to any other existing systems, because this person is not restrained by the existing system. His/her claim that there are no loopholes in the system is unconvincing. Just as the saying goes, every coin has two sides. In judging things, we should always look at both sides of the coin - no matter what education system we are in, it should not be totally negative or totally positive.

Take the China's college entrance examination, Gaokao, as an example. Some people complain about the ruthlessness of that and fight for justice for the oppression of students, but they can hardly imagine that there are so many people who see the college entrance examination as the only way out of the mountains and out of their terrible status quo. The examinee of Gaokao should also be grateful for the opportunity to receive education, because there are many people who cannot even take the examination since the number of students in junior high school is not in proportion to the number of students entering high school or the number of students registering for the Gaokao.

It is a pity that for many years that there are people not favored by the existing system or not allowed to receive the education they want because of the limitations from all aspects. The college entrance examination has been oriented by math, physics, chemistry, etc, those so-called hardcore academics. However, it is necessary since a country needs to pass its own talent selection system and need sophisticated talents to help it become strong and ensure its security. If a country is not safe enough, education or any other progress in a country is an empty talk.

\subsection{The utilitarianism in western education system}

Utilitarian education is not absent from the Western educational system as well, and the experience of the heroine in the film, an education, is a case in point_- it took place in London, England in the 1960s. Such a situation is not uncommon during these days. For example, when students apply to universities, many students are torn between the top undergraduate universities and the top universities. Or they are going to study a major that they are not that interested in but that can make money or help them in the future. This choice puts students in a dilemma, because no one can predict the future.

\subsection{Summary}

Educational diversity is especially important because everyone has different potential and fits into different systems. Whether the cost of education is affordable or not is also a necessary condition for a person to receive proper education. Therefore, the stability and security of a country, the sustainable development of economy and the improvement of citizens' personal living standards are particularly important. The overall upward shift of society may lead that no one is willing to take the lowest level of work, so some job vacancies are need to be prepared for, as well as the emergence of new jobs and exploration of new fields. Different people have different levels of education, different family environments, different horizons, different needs, and different sources of satisfaction. Is there an ideal world loved by all the people? Only by staying compatible, constantly trying, changing, subverting, innovating, can lead a better life. Hopefully, nobody will be let down, so that everyone can receive the education suitable for themselves, everyone can play their own value, learn something, find their own inner peace. Although there is a gap between ideal and reality, people are all moving towards a better life. It is hoped that educational resources can equally benefit everyone.

\section{CONCLUSION}

By analyzing the plot of the film, an education, the term "the ideal education" is defined in this paper. In addition, the deviation between educational ideal and educational practice is pointed out. What is more, the disadvantages of utilitarian education and the fuzziness of educational purpose to individuals and society, as well as the possible outcomes that might occur due to the failure to achieve balance in "developing the abilities" and "cultivating the person itself" are discussed. In the discussion section, the author compared the current education system and demonstrated the inevitability and necessity of utilitarian education in the stage of social development. Besides, the co-existence of utilitarian education in Chinese and western education systems and cultures is mentioned. By writing this paper, the author calls for attention to diversified education, encourages economic development and social progress, so as to eventually promote the development of education and solve the problem of education quality.

To further extend this topic, it is better to combine some any other relevant documentaries or films to help the audiences develop a better understanding of the topic, or analyze from more diverse perspectives. Moreover, to be more realistic and practical, it can be combined with the analysis upon the different education systems under different national conditions to understand the formation of the education systems and compare the characteristics of those in order to provide a better plan with feasibility. 


\section{ACKNOWLEDGMENT}

First and foremost, I would like to show my deepest gratitude to Mr. David Howard, the professor in the University of Southern California, who helps me explore different cultures behind various films and inspires me to lean in to do my own research upon education. Then, I would like to thank my parents, all my teachers who ever taught me and friends I met till now to make me become such a person currently. The last but not the least, I am glad that I have the honor to experience both Chinese style education and Western style education which provides me a direct approach to compare both systems and invoke my contemplation and critical thinking.

\section{REFERENCES}

[1] Website: Toppr. Retrieved on June 10, 2020, from: https://www.toppr.com/guides/essays/importance-of-educ ation/

[2] W. M. Sloan. What Is the Purpose of Education? July 2012. Retrieved on June 10, 2020, from: http://www.ascd.org/publications/newsletters/education-u pdate/jul12/vol54/num07/What-Is-the-Purpose-of-Educati onc.aspx

[3] Annex IX GENERAL COMMENT NO. 1 (2001) ARTICLE 29 (1): THE AIMS OF EDUCATION. Retrieved on June 10, 2020, from: https://www.right-to-education.org/sites/right-to-educatio n.org/files/resource-attachments/CRC_General_Comment _1_en.pdf.

[4] R. Lord. Testing Much? The Pros And Cons Of Exams In Education. July 17, 2019. Retrieved on June 10, 2020, from:

https://hk.asiatatler.com/life/testing-much-pros-cons-exam $\mathrm{s}$

[5] Dr. M. L. King Jr. Morehouse College Student Paper, The Maroon Tiger, in 1947. Retrieved on June 10, 2020 , from:https://www.drmartinlutherkingjr.com/thepurposeofe ducation.htm

[6] Website:Young Minds. Retrieved on June 10, 2020, from:https://youngminds.org.uk/about-us/media-centre/pr ess-releases/rebalance-education-system-to-focus-on-well being-say-teachers-and-parents/

[7] Y. Zhao. High Test Scores, Low Ability. December 4, 2010. Retrieved on June 10, 2020, from: https://www.nytimes.com/roomfordebate/2010/12/02/wha t-is-a-college-degree-worth-in-china/high-test-scores-lowability 